Constitución y ley interpretativa. Algunas notas sobre una paradoja y peligros relativos a este tipo de ley Constitution and statute interpretative. Some notes concerning an paradox and dangers relative to be statute type Francisco Zúñiga Urbina páginas $255-281$

\title{
CONSTITUCIÓN Y LEY INTERPRETATIVA. ALGUNAS NOTAS SOBRE UNA PARADOJA Y PELIGROS RELATIVOS A ESTE TIPO DE LEY*
}

\section{CONSTITUTION AND STATUTE INTERPRETATIVE. SOME NOTES CONCERNING AN PARADOX AND DANGERS RELATIVE TO BE STATUTE TYPE}

\author{
Francisco Zúñiga Urbina**
}

\begin{abstract}
RESUMEN
El trabajo se aproxima al tema de la interpretación de la Constitución a través de la "ley interpretativa", nuevo tipo de ley incorporada a la taxonomía del artículo 66 , y que posee, dada su naturaleza o contenido material, un carácter excepcional y limitado, no exenta de paradojas y peligros.
\end{abstract}

\begin{abstract}
The paper approach theme of the constitutional interpretation by means of the "interpretative act", new class of act or statute to incorporate an classification this articyle 66 and that to posses, give to nature or material contents, an exceptional character and limited, no exempt paradox and dangers.
\end{abstract}

\section{PALABRAS CLAVES}

Constitución, estructura normativa, ley interpretativa.

\section{KEY-WORDS}

Constitution, normative structure, "interpretative act".

* Ponencia basada en Informe expedido a la Comisión de Constitución, Legislación, Justicia y Reglamento del H. Senado acerca del artículo $2^{\circ}$ del Proyecto de Ley que establece medidas contra la discriminación.

** Profesor de Derecho Constitucional de la Universidad de Chile y de la Universidad Diego Portales. Correo electrónico: zdc@zdcabogados.cl 


\section{I.- Prolegómenos}

El constitucionalismo moderno en sus diversas tradiciones o vertientes (liberal, democrática y social) admiten como paradigma dominante un concepto normativo de Constitución distante del paradigma decimonónico de un concepto político, retomando así la tradición de los monarcómacos. Conforme a este concepto normativo la Constitución es la ley suprema u orden jurídico fundamental, fruto de la autodeterminación política del pueblo y recipiente de compromisos que aquilatan, en un techo ideológico abierto o plural, todo lo que es determinante para los fines y estructura normativa de la Carta Política. Asimismo, la Constitución cumple ciertas funciones básicas y tiene un contenido usual: el estatuto del poder político estatal y el estatuto o carta de derechos, deberes y garantías constitucionales. ${ }^{1}$

La Constitución entendida desde una aproximación estructural como ley suprema, tiene dos dimensiones: es la norma básica de un sistema en la medida que determina la producción válida de las normas jurídicas de todo el ordenamiento jurídico (Kelsen), y es un subsistema de normas iusfundamentales que operan como reglas de competencia (Ross), un Derecho de la Constitución compuesto de dos partes: en el lenguaje del criticado dualismo tradicional, de un derecho objetivo y de un derecho subjetivo. De este modo, los principios de constitucionalidad: supremacía formal-material, valor normativo y eficacia normativa, no son sino consecuencia de su autoafirmación de supraordenación jerárquica de un sistema cerrado y completo de normas. $^{2}$

Así las normas iusfundamentales de conducta (dirigidas a los sujetos de derecho) y de organización (dirigidas al Estado), en el añoso lenguaje de Posada de la parte "dogmática" y de la parte "orgánica" de la Constitución, están enderezadas a tener eficacia normativa, directa o indirecta, positiva o negativa, con o sin desarrollo infraconstitucional, y vinculan a todos los poderes públicos y a todas las personas o sujetos; especialmente vinculan a los tribunales de

1 Sobre la Constitución y el constitucionalismo histórico una sinopsis en el libro de Fioravanti, Mauricio, Constitución. De la antigüedad hasta nuestros días. Editorial Trotta, Madrid, 2001 y de Grimm, Dieter, Constitucionalismo y derechos fundamentales, (Estudio preliminar A. López Pina). Editorial Trotta, Madrid, 2006, pp. 107-153. Sobre la Constitución formal-material un texto obligado de Otto Pardo, Ignacio de, Derecho Constitucional. Sistema de Fuentes. Editorial Ariel, Barcelona, 1985, pp. 28-56; y del mismo autor Lecciones de Derecho Constitucional. Introducción. Giastur Ediciones, Oviedo, 1980, pp. 79-107.

2 Consultar a Kelsen, Hans, Teoría Pura del Derecho, (trad. R. J. Vernengo). $7^{\mathrm{a}}$ Ed. Editorial Porrua-UNAM, México DF., 1993, pp. 232-235; y Teoría General del Derecho y del Estado, (trad. E. García Maynez). $3^{\text {a Ed. }}$ UNAM, México DF., 1969, pp. 146-152. De Ross, Alf, Sobre el derecho y la justicia, (trad. G. Carrió), Eudeba, Buenos Aires, 1963, pp. 76-81 y "On the concepts "State" and "State organs" in constitutional law", en Scandinavian Studies in law, N 5 (1961), pp. 11-129, y su traducción al español de Vásquez, E. A. en recopilación titulada: El concepto de validez y otros ensayos. $1^{\mathrm{a}}$ Ed., 1991, $4^{\mathrm{a}}$ Ed., 2001. Fontamara, México DF., 2001, pp. 73-92. 
Constitución y ley interpretativa. Algunas notas sobre una paradoja y peligros relativos a este tipo de ley Constitution and statute interpretative. Some notes concerning an paradox and dangers relative to be statute type

justicia en la tutela del derecho propia de la función protectora-represiva que cumple el derecho, exigen de un custodio jurisdiccional supremo y obligan a una "interpretación conforme" a la Constitución.

En el fondo las normas constitucionales asumen el carácter de normas o reglas de competencia en el sentido que establecen, habilitan, limitan u orientan el poder estatal; de suerte que las normas de conducta son reglas de competencia negativa o prohibitiva, puesto que fijan límites a la actividad del poder estatal, como ocurre con las normas relativas a derechos que delimitan un ámbito de personalidad (subjetividad y autonomía); y las normas de organización son reglas de competencia positiva o afirmativa, en la medida que son constitutivas de órganos, atributivas de competencia y procedimientos, y determinantes en la fijación de relaciones interinstitucionales, pudiendo además estas normas fijar directrices u orientaciones al poder del Estado o establecer pautas para la hermenéutica de la Constitución o de sus partes componentes, estableciendo programaciones, objetivos, medios y fines; como ocurre en nuestro país al concebir la Constitución a la Administración del Estado como una Administración para el desarrollo.

En este punto no podemos dejar de enunciar una elemental precisión metodológica: la aproximación estructural del Derecho a la Constitución, que explica qué es el derecho y de qué se compone, converge con una aproximación funcional que busca explicar para que sirve el derecho, más allá de la función protectora-represiva, abriéndose a funciones distributiva, redistributiva y promocional, situando al derecho en general y a la Constitución en particular ante el cambio social.

Estas normas iusfundamentales, sean permanentes o transitorias, tienen una estructura normativa interna abigarrada, heterogénea y con notas características basales a las que nos referiremos en el apartado siguiente y que hacen a la peculiaridad de la Constitución; obviando abordar la debatida cuestión del "valor" de los preámbulos de una Constitución.

De esta estructura normativa interna, y compatible con la distinción básica entre normas de conducta y normas de organización, es posible identificar, siguiendo los aportes de Huber, Scheuner y Rubio Llorente, las normas iusfundamentales siguientes: normas declarativas y principios fundamentales (normas de principio), normas de reconocimiento de derechos, normas de reconocimiento de garantías (institucionales, normativas y jurisdiccionales o procesales), habilitaciones, mandatos, prohibiciones y directrices a los poderes públicos, normas sobre producción de normas (incluidas las normas de reforma constitucional), normas de reenvío, y normas orgánicas (sobre organización y funcionamiento de órganos del Estado, normas de procedimiento, normas atributivas de competencias). Otro autor germano K. Stern nos propone como clasificación de normas constitucionales, la siguiente: normas de competencia, normas de creación de órganos del Estado, normas de procedimiento, normas de reforma o revisión constitucional, disposiciones normativas, normas sobre derechos fundamentales, normas sobre 
garantías, normas sobre estructura y fines del Estado, normas con mandatos constitucionales, normas jurídico materiales y normas jurídico organizatorias ${ }^{3}$. Huelga señalar que desde la heterogeneidad reseñada las normas iusfundamentales pueden ser encuadradas tipológicamente en más de una de estas categorías taxonómicas.

La concepción dominante de la Constitución como ley suprema y su autorreconocimiento de valor y eficacia normativa, permite sostener que ésta es el tronco a partir del cual todas las ramas del derecho nacen, y proyecta sus efectos duraderamente sobre tales ramas y además es en sí como subsistema normativo un derecho que bajo determinadas condiciones es directamente aplicable. Lo anterior conlleva en la teoría constitucional contemporánea a un cierto exceso bajo la etiqueta de "fuerza normativa"de la Constitución que hace de ésta un demiurgo normativo, deus ex machina o totum normativo; que deviene en verdadera patología y que denominamos "fetichismo constitucional", la que hemos criticado sistemáticamente en diversos trabajos apelando a un sinceramiento y realismo mínimos.

Esta patología tan extendida en la teoría constitucional y sus autores contemporáneos, por un lado ha "sacralizado" política y jurídicamente la Constitución declarándola suprema, inviolable y normativa y por otro, a la hora de la verdad, enfrentados con el "barro del ídolo que ellos mismos han creado, se ven obligados a acudir a fórmulas incoherentes con sus posiciones dogmáticas" (Nieto). En el fondo, el "fetichismo constitucional" confunde la normatividad (valor y eficacia normativa) con la aplicación directa u "operatividad" de normas constitucionales o justiciabilidad y aquejados de un acendrado panjudicialismo refuerzan un amplio campo a la discreción del control jurisdiccional, introduciendo a los tribunales y al Tribunal Constitucional en la creación de derecho, exorbitando así su funcionalidad destructora ("legislador negativo") de normas inconstitucionales o reintegrativa del ordenamiento jurídico.

Nuestro propósito en este lugar es muy modesto: consiste en dar cuenta sumariamente de una estructura normativa interna y fines de la Constitución, que hacen de ésta un "marco abierto" o "abanico de posibilidades", en razón de su extensión, polivalencia y diseño normativo iusfundamental, que determina los alcances del desarrollo normativo infraconstitucional, de la hermenéutica constitucional y de cuándo debe entrar a tallar la reforma constitucional con sus órganos y procedimientos preestablecidos o "poder constituyente derivado" .

3 Consultar recopilación de trabajos de Rubio Llorente, Francisco, La forma del poder. Editorial CEC, Madrid, 1993, pp. 88-89. También el libro de Requejo P., José Luis, Sistemas Normativos, Constitución y Ordenamiento. Mc Graw, Madrid, 1995. De Klaus, Stern, Derecho del Estado de la república federal alemana, (Trad. J. Pérez Royo y P. Cruz Villalón). Editorial CEC, Madrid, 1987, pp. 265-279.

4 Sobre la interpretación y sus reglas consultar a Wroblewski, J., Constitución y teoría general de la interpretación jurídica. Editorial Tecnos, Madrid, 1985 y Alonso, Enrique, La interpretación de la Constitución. Editorial CEC, Madrid, 1984.En el continente un texto clásico, muy citado por la jurisprudencia constitucional, es de Linares Quintana, Segundo V., Reglas para la Interpretación Constitucional según la doctrina y jurisprudencia. Editorial Plus Ultra, Buenos Aires, 1987. 


\begin{abstract}
Constitución y ley interpretativa. Algunas notas sobre una paradoja y peligros relativos a este tipo de ley Constitution and statute interpretative. Some notes concerning an paradox and dangers relative to be statute type
\end{abstract}

Precisamente, la conexión Constitución-ley interpretativa se da en el contexto dual del desarrollo infraconstitucional y de una modalidad específica de interpretación de la ley suprema: la interpretación auténtica, no exenta de paradojas, problemas y peligros.

\title{
II.- Constitución: Estructura Normativa e Interpretación
}

Constituye un tópico afirmar que el derecho constitucional es la juridificación de la política, expresión de la racionalización del poder propia del Estado moderno y su forma jurídicopolítica es el Estado de Derecho, y su síntesis con la forma política estatal: republicanodemocrática, es la denominada "democracia constitucional" o "Estado constitucional". A partir de este tópico se hace necesario establecer en la Constitución un techo ideológico, usualmente abierto o plural, y funciones precisas por una parte, y una composición de normas constitucionales que exige una taxonomía adecuada y una estructura normativa interna por otra parte, todo lo cual permite concebir a la Carta Política como "ley peculiar" o "naturaleza especial” (Linares Quintana) y, debemos añadir, distinta a la legislación.

Luego, para nuestro propósito es necesario recoger algunas ideas acerca de la estructura normativa interna iusfundamental y cómo esta estructura determina su desarrollo infraconstitucional y su hermenéutica. En este sentido nos recuerda Martínez Sospedra: " $L a$ afirmación de la Constitución como ley peculiar se debe tanto a su especial significación política como a su no menos especial posición en el ordenamiento, y ello tiene reflejo tanto en las técnicas de redacción de la Constitución misma como en las funciones que en el sistema jurídico la ley fundamental cumple. Finalmente tiene un papel decisivo a la hora de afrontar una cuestión capital en un Estado como el nuestro en el que la Constitución es norma de aplicación directa y existe un sistema organizado y eficiente de justicia constitucional, a saber, el problema de la interpretación de la Constitución misma”. En suma, observa Hesse, las normas iusfundamentales son peculiares por su rango o posición jerárquica, clase de sus reglas, condiciones de su validez y su capacidad para imponerse a la realidad social; lo que obliga a armonizar la supremacía y vinculación a la Constitución con su carácter abierto, indeterminación y amplitud de sus normas, en su lenguaje y estructura; permitiendo concluir lógicamente que estas normas "no son completas ni perfectas".

Por otra parte, resulta tradicional para los operadores jurídicos formados por largo tiempo

Martínez Sospedra, Manuel, Estado y Constitución. Una introducción. Fundación Universitaria San Pablo CEU, Valencia, 1991, p. 257, y Derecho Constitucional español. Fundación Universitaria San Pablo CEU, Valencia, 1995, pp. 68-72. Del eminente jurista germano Konrad Hesse se consulta su trabajo introductorio en la obra colectiva Manual de Derecho constitucional. IVAP-M. Pons, Madrid, 1996, y Escritos de Derecho Constitucional, (trad. P. Cruz Villalón). Editorial CEC, Madrid, 1983, p. 17. También del administrativista español Alejandro Nieto, "Peculiaridades jurídicas de la norma constitucional". RAP, No 100/02, Vol. 1, 1983, recogido en recopilación Estudios de Derecho y Ciencia de la Administración. Editorial CEPC, Madrid, 2001, pp. 85-123. 
en una cultura legiscentrista el empleo de reglas y criterios hermenéuticos consolidados, v.gr. las reglas de Savigny, esenciales para la interpretación y aplicación de la legislación, en torno a las cuales se han diseñado las principales técnicas de hermenéutica. Ello contrasta con la hermenéutica constitucional en que la "naturaleza especial" (Linares Quintana) o de ley peculiar que posee el Derecho de la Constitución, determina reglas hermenéuticas específicas. La ley y la legislación tienen una finalidad distinta de la ley constitucional y su estructura o diseño difiere notablemente del de ésta.

La ley y la legislación están diseñadas nos advierte Martínez Sospedra:

"1.- Para el desarrollo y aplicación de políticas sectoriales y concretas. La ley ordinaria es, normalmente, una ley dirigida a ordenar un sector concreto de la sociedad, y a ordenar dicho sector de la realidad social en razón de una política determinada, escogida por el legislador de entre una pluralidad de políticas posibles. Por muy amplio que sea el campo normativo de la ley ordinaria este es siempre sectorial y expresa, por ello, una ordenación inspirada en políticas asimismo sectoriales.

2.- Proporcionar, en la medida de lo posible, una solución legal única a cada problema. En tanto que instrumento de una política concreta la ley ordinaria está diseñada para dar en cada caso una solución legal única o una gama muy reducida de soluciones legales estrechamente ligadas o emparentadas entre sí. En la medida de lo posible el ideal de la ley ordinaria es la univocidad, obtener el resultado de un significado único, preciso, de cada uno de sus enunciados, siendo en este sentido el caso extremo el de las normas penales. Ideal de univocidad que es consecuencia del propósito político unitario, y del carácter sectorial de la ley, y que explica la utilización intensiva por el legislador de la terminología técnico-jurídica, dado que esta está diseñada, precisamente, para reducir la equivocidad mediante la precisión conceptual y terminológica.

3.- La huida del lenguaje ordinario. La consecuencia necesaria de este planteamiento es la búsqueda de un lenguaje peculiar para expresar y comunicar las normas, de donde una tendencia muy marcada a la especialización terminológica en las diversas ramas del saber jurídico. La exigencia del lenguaje técnico-jurídico propio de cada rama del Derecho, que vienen referidas a grandes áreas o sectores de la realidad social, así como la afirmación de la autonomía que cada una de aquellas reclama para la fijación de sus propios conceptos entrañan el progresivo abandono del lenguaje común como instrumento para expresar las normas a favor de la terminología propia de cada rama del Derecho. Lo que, dicho sea de paso, aleja de la norma al ciudadano común y dota de una no despreciable influencia política a esa suerte de opinión pública de los juristas que llamamos "la doctrina". 
Constitución y ley interpretativa. Algunas notas sobre una paradoja y peligros relativos a este tipo de ley Constitution and statute interpretative. Some notes concerning an paradox and dangers relative to be statute type

4.- $\quad$ Una duración limitada. El propósito ordenador directo de la ley ordinaria conduce a la limitación de la vida de la misma. En una sociedad en rápido cambio de las condiciones económicas, técnicas, sociales, etc., una normativa que buscar ordenar un sector de la realidad social para orientarlo según opción política concreta está fuertemente sujeta al condicionante de la cláusula rebus sic stantibus. La ley ordinaria nace con vocación de permanencia, pero su fundamental propósito ordenador de un sector concreto en una realidad social en rápido cambio surte una fuerte permanencia sólo es posible en aquellos sectores de la realidad en los que los cambios son muy lentos o inexistentes, en los que las inercias son extremadamente fuertes, en la medida en que tales sectores tienen una importancia reducida -y aún menguante- en la sociedad moderna, lo que caracteriza a la mayoría de aquellas es, ciertamente, su escasa estabilidad.

5.- La importancia de la solución más legal. Es el objetivo de la ley ordinaria. En tanto que instrumento de una política sectorial concreta de ordenación la efectividad de la norma ordinaria exige la imposición de los operadores jurídicos una estrecha vinculación por la ley. Por ello administrar la ley es ejecutar la ley. La ley no se limita a habilitar a los poderes públicos y a los particulares para desarrollar actividades de aplicación que, de alguna manera, son discrecionalmente escogidos por estos, la ley impone a sus administradores no un marco o unas orientaciones genéricas, sino unas prescripciones detalladas que conducen a una gama muy reducida de opciones entre las que el administrador tiene que optar, en el mejor de los casos, y, si es posible, imponer una solución única" ${ }^{\text {. }}$

En cambio, huelga decirlo, la norma constitucional se halla muy alejada del diseño referido, obedece a finalidades distintas, tiene un campo de aplicación diferente, se redacta mediante técnicas propias, tiene una amplia vocación de permanencia y no busca tanto prescribir políticas como limitar las opciones que los actores políticos pueden escoger legítimamente, usualmente con techo ideológico abierto. Martínez Sospedra nos dice: "La ley constitucional difiere de la ley ordinaria por una razón fundamental: el objeto propio de la ley constitucional no es un sector de las relaciones sociales, sino su totalidad; la finalidad de la ley constitucional no es establecer ordenaciones con vistas a la imposición de políticas concretas, sino establecer un marco general de relaciones jurídicas que, determinando los modos, condiciones y formas de producción de reglas de Derecho, permita el desarrollo en normas concretas-ordinarias- de políticas diferentes". Usando un símil singularmente adaptado, el objeto propio de la Constitución es establecer "las reglas del juego político y no diseñar las singulares estrategias 
y tácticas del juego mismo"; ya que la Constitución condensa derecho y política en un orden fundamental o marco, lo que la aleja de poseer un "carácter sacro" (Nieto), más bien su carácter es derechamente profano.

De lo expuesto podemos enunciar las características basales del diseño o estructura normativa de la Constitución, que como hemos dicho es esencial para determinar el alcance de su desarrollo infraconstitucional y de su hermenéutica. De estas características basales subrayamos con Martínez Sospedra las siguientes:

1.- La Constitución es un marco general. No hace falta recurrir a la noción clásica de la Constitución como actualización del contrato social para convenir que la función propia de la ley fundamental es establecer la ordenación general del Estado, esto es establecer aquellas reglas jurídicas que determinan quien está legitimado para ejercer el poder público, en que condiciones y con que límites puede el mismo ser legítimamente ejercido y que finalidades generales, en cuanto constituyen un auténtico proyecto político de Estado, deben ser perseguidas mediante las diferentes políticas concretas cobijables bajo la Constitución misma. Si la Constitución es la norma de cabecera del ordenamiento, en la que diversas ramas del mismo entran sus respectivas "têtes de chapitre" se debe precisamente a ese hecho.

2.- La Constitución es norma de vocación pluralista. Por su propia naturaleza la Constitución no es norma llamada a prescribir políticas concretas, antes bien es norma dirigida a establecer la estructura general del ordenamiento y a facilitar, de este modo, la definición, la adopción, el desarrollo y actuación de una pluralidad de políticas concretas. No hay una sola política constitucional, la Constitución ampara una diversidad de políticas posibles y se limita a excluir, de la totalidad de las políticas adoptables, tan sólo aquellas que no son compatibles con la ordenación general de la sociedad que la misma prescribe, con el proyecto de Estado que la misma incorpora. Nos encontramos aquí en las antípodas de la ley ordinaria. En términos generales nunca hay una solución única, una sola solución constitucional a los problemas que se presenten, siempre hay diversas políticas legítimas sobre sectores concretos dentro del marco constitucional, expresión que difícilmente puede ser más ilustrativa.

3.- La Constitución no contiene, como regla general, normas inspiradas en el propósito de lograr una solución única. La consecuencia resulta obvia tras lo dicho. La apertura a una pluralidad de políticas (sobre cualquiera de las materias no contempladas por la Constitución, e incluso sobre aquellas que la Constitución de algún modo contempla), implica la limitación de la norma constitucional a la fijación de normas generales de orientación que pueden ser concretadas en orientaciones políticas diversas 
Constitución y ley interpretativa. Algunas notas sobre una paradoja y peligros relativos a este tipo de ley Constitution and statute interpretative. Some notes concerning an paradox and dangers relative to be statute type

y, por tanto, en normas ordinarias también diversas. De ahí que las técnicas de redacción de la Constitución sean diversas a las de la ley ordinaria y que, en consecuencia, la interpretación constitucional tenga exigencias diferenciadas.

4.- $\quad$ La Constitución tiene vocación de perpetuidad. Lo que no es más que una consecuencia de su naturaleza de ordenación general, de norma de cabecera y marco de las demás normas. Ello exige, asimismo, técnicas redaccionales $y$ de interpretación peculiares, y es la causa final de determinadas instituciones, destinadas a garantizar la continuidad del ordenamiento general mediante su adaptación. Esa es la razón de ser la jurisprudencia constitucional o de los sistemas de reforma constitucional.

5.- Legislar no es ejecutar la Constitución. Por tanto la relación entre la Constitución y las normas ordinarias no es homologable a la que pueda existir entre la ley ordinaria y las normas subordinadas a la misma. No existiendo una única solución constitucional, una sola ordenación de materia concreta que complete y agote las posibilidades constitucionales, mas bien al contrario, al existir siempre una pluralidad de opciones constitucionalmente legítimas la opción por un determinado tipo de ordenación legal ordinaria entra dentro de la esfera de acción legítima del legislador, del Parlamento, siempre que no entre en contradicción con el orden vinculante de convivencia constitucionalmente fijado" ${ }^{\text {. }}$.

Establecida esta cuestión: la Constitución, porque busca finalidades diferentes a la ley y a la legislación, y posee un diseño o estructura normativa distinta, no es susceptible de ser redactada de acuerdo con las mismas técnicas que aquella, ni puede ser interpretada del mismo modo.

Junto al diseño y estructura normativa de la Constitución, y en razón de sus principios de constitucionalidad: supremacía, valor normativo y eficacia normativa, posee una estabilidad normativa consecuencia de su jerarquía en el sistema, la que es asegurada a través de la técnica de la rigidez, cuando no también a través de la imposición de límites materiales o "cláusulas de eternidad"al poder de reforma constitucional, límites que no están presentes en nuestro Derecho de la Constitución, el cual admite en iter complejo la reforma total y parcial, diferenciando quórum ordinario y extraordinario por capítulos del texto constitucional.

Tal rigidez y jerarquía de la Constitución en el sistema no excluyen la elasticidad espacial y temporal de las normas constitucionales, elasticidad que deriva de la "polivalencia 
semiológica" de las palabras y de las locuciones empleadas y de sus conexiones. En cuanto a "palabras", "locuciones" y sus "conexiones" Predieri señala: "Unas y otras son escogidas a menudo por su elevado grado de elasticidad, por ser umbestimmte Begriffe. Se recurre a ellos para dejar amplios márgenes al poder legislativo, o normativo, ya en sentido espacial, para la precisión extensiva o reductiva de los conceptos a través de normas de grado inferior, ya en dirección temporal. En esta última los cambios de campo semántico actúan de modo complejo. En parte por las variaciones en el lenguaje común o en las jergas de especialistas, a las que la normativa recurre cada vez más, pero más a menudo aún por las variaciones del lenguaje normativo y judicial, y del metalenguaje de los juristas" ${ }^{\text {. }}$

La Constitución como "orden fundamental", "marco general” o "abanico de posibilidades", exige el recurso a técnicas peculiares, las normas de cabecera o "têtes de chapitre" a que se refería P. Rossi en los albores de la disciplina a mediados del siglo XIX, las que deben satisfacer exigencias que no se hallan presentes en la ley y legislación. En este orden de ideas, son cuatro las técnicas más usuales y extendidas en la conformación de las normas constitucionales: el uso abundante de la normación incompleta, la frecuencia del recurso a conceptos jurídicos indeterminados, la mayor relevancia del lenguaje ordinario y la relativa rareza del recurso al lenguaje técnico-jurídico y el uso frecuente de la remisión normativa.

En palabras de Martínez Sospedra el lenguaje con que se escribe la Constitución, recurre a las técnicas siguientes:

"1.- El recurso a la técnica de la normación incompleta. Una característica llamativa del lenguaje constitucional es la frecuencia con la que a la hora de definir las normas constitucionales se recurre a la técnica de la normación incompleta. Dicho recurso implica, en primer lugar, que la Constitución establece una parte de la normación de una institución, materia o asunto, pero tan sólo una parte de la misma. En segundo lugar, que el texto constitucional llama al Legislador ordinario a completar el programa normativo que el propio texto ha dejado incompleto, de tal modo que éste debe realizar su tarea marcado por aquella parte de la normación constitucionalmente fijada, que le viene impuesta por razón de la supremacía de la norma constitucional. En tercer lugar que, pese a ello, el Legislador cuenta con un apreciable margen de maniobra, con una esfera de acción en el seno de la cual si bien la producción normativa viene vinculada parcialmente por la norma constitucional el Parlamento cuenta con un margen de acción, con una esfera de discrecionalidad importante, que lo

Predieri, Alberto, "El sistema de las fuentes del derecho", en libro colectivo La Constitución Española de 1978. Estudio Sistemático. $2^{\circ}$ Ed., 1981, Reimp., 1988. Editorial Civitas, Madrid, 1988, p. 202. 
Constitución y ley interpretativa. Algunas notas sobre una paradoja y peligros relativos a este tipo de ley Constitution and statute interpretative. Some notes concerning an paradox and dangers relative to be statute type

es tanto más cuanto mas incompleta sea la norma constitucional. En cuarto y último lugar que la Constitución renuncia a la aplicación inmediata y directa de su propia norma precisamente por razón de la voluntaria incomplitud, sustituyendo ésta por un mandato dirigido al Legislador para que éste complete la normación constitucional ejerciendo una discrecionalidad reducida que, empero, permite una pluralidad de normaciones de desarrollo y concreción. De éste modo la determinación concreta de la ordenación de materias, figuras, órganos o instituciones depende de la colaboración entre el Constituyente y el Legislador ordinario, instrumentada mediante el deber de producción normativa que recae sobre éste último y sobre el reparto del programa normativo efectivo por la Constitución. Como consecuencia la normación correspondiente se descompone en dos elementos: uno permanente, dotado de la supremacía propia de la ley fundamental, que se impone al Parlamento, otro complementario del anterior, variable con el tiempo, las opciones políticas de la mayoría parlamentaria y las necesidades del proceso político o el cambio social. La razón de ser del recurso a esta técnica, que permite combinar elementos permanentes y variables en una misma normativa, es doble: de un lado permitir una ampliación notable del campo de acción de pluralismo político, de las mayorías cambiantes, sin necesidad de establecer un núcleo normativo completo dotado de la estabilidad propia de la Constitución, del otro facilitar la adaptación de la ley fundamental a las cambiantes circunstancias políticas y sociales, sin perjuicio de un afirmar un núcleo normativo permanente [...].

2.- El uso abundante de conceptos jurídicos indeterminados. Si bien el uso de conceptos jurídicos indeterminados no es per se una característica de la formación constitucional, no obstante sí lo es la abundancia e importancia de su uso en la ley fundamental. Aunque más destacada en unas partes de la Constitución que en otras [...] resulta llamativa la particular afición del constituyente por esta técnica. La razón de ser de tal uso no es difícil de determinar, y está ligada a la vocación de permanencia de la ley fundamental. Como es bien sabido tales conceptos tienen como característica esencial el carecer de un significado preciso, aunque éste es concretizable por los operadores jurídicos y concretizable, en su caso, por jurisdicción.

Pues bien, en el lenguaje constitucional su abundante presencia se debe al hecho de que no se limitan a operar como cláusulas de cierre de la normativa concreta, como suele suceder en su uso en la legislación ordinaria, sino que, sin perjuicio de cumplir dicha función, establecen una normativa constitucional imprecisa pero determinable mediante el recurso a conceptos de orden jurídico, pero también sociológico, político, cultural, etc. que 
dota de flexibilidad a la formación constitucional, permite la evolución de la Constitución viva sin necesidad de recurrir a los costes y riesgos de la revisión constitucional y sin cesuras en la continuidad de la formación misma. De ahí su uso intensivo en aquellas partes de la Constitución de carácter más acentuadamente doctrinal, más allá del uso tradicional de las cláusulas de cierre, que también se da.

Naturalmente ello no facilita la tarea de la interpretación constitucional, no es casual que sea en torno a tales conceptos donde se halle el punto nodal de la querella, tradicional en el constitucionalismo USA, entre los partidarios de la strict construction y quienes sostienen la actualización de la ley fundamental, entre otras cosas porque obliga a un recurso intensivo a técnicas peculiares de interpretación y tiende a acentuar la función práctica del recurso a los principios y orden de valores de la Constitución, pero, en contrapartida, su uso tiene ventajas evidentes. Desde luego el problema que el uso de tales conceptos plantea es creciente con el tiempo, pues obviamente recursos interpretativos de gran autoridad y certeza como el recurso a los trabajos parlamentarios como medio de acreditación de la "voluntad del constituyente" - ven su valor drásticamente disminuido con el transcurso del tiempo en cuanto al contenido de estas cláusulas se refiere [...].

3.- El uso del lenguaje: preferencia por el no técnico. No hace falta comulgar con quienes ponen el acento en la función pedagógica de la Constitución, ni en quienes subrayan su utilidad a efectos de propaganda, para tomar nota del hecho de que las Constituciones tienden a emplear con frecuencia en sus textos el lenguaje ordinario, o, por decirlo de otro modo, que no emplean el lenguaje técnico-jurídico con la asiduidad con que lo emplea el legislador ordinario. Las razones de esta conducta son varias, y algunas de ellas deben resultar evidentes a la vista de lo que llevamos dicho. En efecto, la mayor relevancia del lenguaje no técnico implica, en primer lugar, el deseo de huir de una legislación diseñada para procurar una solución legal única, o, dicho en términos positivos, la voluntad de hacer posible una pluralidad de desarrollos legislativos posibles de las normas constitucionales concretas; en segundo lugar permite una mayor flexibilidad de la formación constitucional, al estar el lenguaje ordinario más abierto a la mutación del significado de sus términos que el técnico-jurídico; en tercer lugar habría que señalar que el uso del lenguaje ordinario hace más fácil la inteligencia de la Constitución por los legos en derecho y que, en consecuencia, facilita el control del cumplimiento de la misma y de sus desviaciones, tanto por los ciudadanos como por los medios de comunicación, amen de permitir una más fácil difusión de su conocimiento. De ahí la importancia que tiene la forma literaria en el cumplimiento de 
Constitución y ley interpretativa. Algunas notas sobre una paradoja y peligros relativos a este tipo de ley Constitution and statute interpretative. Some notes concerning an paradox and dangers relative to be statute type

las funciones políticas que está llamada a desempeñar la Constitución.

A diferencia de lo que sucede con la técnica anterior la presente no ofrece especial cualificación en su uso por razón de la materia, el uso de expresiones ordinarias es común en todas las partes de la Constitución, si acaso señalar la particular relevancia del mismo en la formulación de las normas de principio, cuya importancia resulta obvia [...].

4.- El uso abundante de las normas de principio y de la remisión normativa. Por último los textos constitucionales hacen un uso intenso de las normas de principio y de las remisiones normativas. La razón de ello es simple. Por lo que toca a las primeras las mismas tienen su espacio natural en la Constitución por razón del objeto de la misma. Si éste es el establecimiento de la estructura general del orden vinculante de convivencia, así como del sistema de ordenación general y de dirección de la sociedad (por eso es Constitución "política"), va de suyo que el tipo de normas que mejor se adapta a ese objeto es, precisamente, el de las normas de principio, en cuanto que estas establece ordenaciones muy generales, verdaderas "reglas de organización” del campo normativo al que se refieren [...]. Por lo que toca a las segundas su uso frecuente en la ley fundamental se debe a razones a estas alturas obvias. El grado máximo de flexibilidad y capacidad de adaptación de la Constitución, y uno de los métodos que mejor se acomoda a su carácter de ordenación general es precisamente la remisión normativa. No obstante se hace necesario añadir que su notable aumento en las Constituciones democráticas se debe a otra razón, no necesariamente menos noble: la necesidad de negociación entre fuerzas políticas y sociales divergentes -e incluso antagónicas- para formular una Constitución democrática viable puede tropezar con el obstáculo de regulaciones sobre las cuales el consenso es momentáneamente imposible. La remisión normativa constituye entonces una técnica particularmente indicada a la hora de establecer lo que Schmitt denominó, no sin cierta ironía "compromisos dilatorios" 9 .

En el contexto descrito no deja de ser una paradoja, no exenta de problemas o peligros de vaciamiento o desconstitucionalización, que la Constitución admita la categoría de "ley interpretativa" en el artículo 66 inciso primero, en la medida que la Constitución y la ley tienen una estructura normativa y fines diversos tal cual se anotó anteriormente. El control de constitucionalidad obligatorio y preventivo previsto en el artículo $93 \mathrm{~N}^{\circ} 1$ de la Carta residenciado en el Tribunal Constitucional, no conjura los problemas o peligros, más bien lo

9 Martínez, Estado, cit. nota n. 5, pp. 263-268. 
contrario, confirma la necesidad de guardar la supremacía e integridad de la Constitución frente a este tipo de legislación.

En cuanto al peligro de vaciamiento y desconstitucionalización de la Constitución por la "ley interpretativa", naturalmente no me refiero al desarrollo infraconstitucional de sus normas, el cual se vale especialmente de la "elasticidad" espacial y temporal de éstas, a la que nos referimos. Tal elasticidad va de la mano de un cambio en el lenguaje de los operadores del derecho (legisladores, políticos, jueces, juristas) y de los destinatarios del poder, que dice relación con las interacciones de la sociedad, la política y el Estado, y que son reflejo de las posiciones de poder que se ocupan y de las consabidas ideologías en sentido fuerte y débil del término, que sirven para enmascarar o justificar decisiones. Este es un vaciamiento y desconstitucionalización tácitas, en el marco de la elasticidad de las normas constitucionales, necesarias para el desarrollo y adaptación de la Constitución a la realidad, ya que observamos una relación dialéctica entre normatividad y facticidad.

Por otra parte, esta categoría o tipo de "ley interpretativa" si está expuesta al peligro de vaciamiento y desconstitucionalización expresas de la Constitución, porque es una fuente infraconstitucional situada en el segmento o grada de la legislación y es expresión de una interpretación auténtica de una norma o precepto constitucional determinado, oscuro, confuso, impreciso o falto de claridad, tipo de ley material y competencialmente limitada al alcance mismo del fruto interpretativo, diferenciada de los otros tipos de leyes por un elemento formal: el quórum preceptivo de aprobación, modificación o derogación: tres quintas partes de diputados y senadores en ejercicio. Este vaciamiento y desconstitucionalización expresas de la Constitución, se funda en último término, en un quiebre del sistema de fuentes del derecho (Pizzorusso) $)^{10}$.

\section{III.- Doctrina y Jurisprudencia Nacional acerca de la "Ley Interpretativa"}

En la doctrina nacional la "ley interpretativa" de la Constitución es concebida como un tipo específico de interpretación, denominada auténtica (las otras denominadas interpretación usual e interpretación doctrinal), que determina el sentido y alcance de una norma jurídica norma constitucional- oscura, falta de claridad o imprecisión; y que se afinca en un principio general del derecho romano, recogido en la máxima: "Ejus est legem interpretari, cujus est condere”. Con todo, Nogueira Alcalá sostiene que la interpretación auténtica de la Constitución comprende: leyes de reforma constitucional del constituyente derivado, leyes interpretativas de la Constitución y sentencias del Tribunal Constitucional ${ }^{11}$. Discrepamos de la amplitud

\footnotetext{
10 Pizzorusso, Alessandro, "Las fuentes del derecho en el Ordenamiento Jurídico Italiano", Revista del Centro de Estudios Constitucionales, No 3 (1989), pp. 269-321.

11 Nogueira Alcalá, Humberto, Lineamientos de interpretación constitucional y del bloque constitucional de
} 
Constitución y ley interpretativa. Algunas notas sobre una paradoja y peligros relativos a este tipo de ley Constitution and statute interpretative. Some notes concerning an paradox and dangers relative to be statute type

dada a la interpretación auténtica, ya que ésta debe ser distinguida de la reforma de la Constitución, de la mutación constitucional y del desarrollo infraconstitucional de ésta ${ }^{12}$. El objetivo de este tipo de interpretación auténtica, como recuerda las Leyes de Partidas, es la “verdadera, recta y provechosa inteligencia de la ley según la letra y la razón”.

De esta suerte, la interpretación de las normas es un procedimiento volitivo e intelectivo que acompaña el proceso de aplicación del derecho, "en su tránsito de una grada superior a una inferior", y que trasunta en decisiones o actos normativos ${ }^{13}$. Consecuencialmente, la interpretación auténtica del derecho compete a los órganos jurídicos de aplicación, y en tal carácter emerge la ley interpretativa. La interpretación auténtica del legislador emerge como voluntad del "autor originario del texto" (Betti) ${ }^{14}$. Nos recuerda Betti que la interpretación auténtica asume el carácter "autoritativo y explica por decirlo así la destinación y función normativa, una eficacia vinculante a la segunda potencia". Tradicionalmente se entiende que la ley interpretativa, en relación a la ley interpretada, adquiere una unidad de significado

derechos. Librotecnia, Santiago, 2006, pp. 81-82: “Se llama interpretación auténtica a aquella interpretación de la ley realizada por el órgano legislativo mediante una ley posterior.

En el ámbito constitucional la interpretación es auténtica, en una primera aproximación, si la realiza el órgano que ha aprobado la Carta Fundamental. Ello lleva a distinguir si la Constitución es otorgada o si es expresión de la voluntad popular. En el primer caso, la interpretación auténtica es posible, si la determina el órgano que ejerce el poder constituyente. En el segundo caso, la hipótesis no tiene mucho sentido, ya que las asambleas constituyentes se disuelven luego de operar, habiendo agotado el mandato para el cual fueron establecidas.

En una segunda aproximación la interpretación auténtica de la Constitución podría ser aquella realizada por un precepto jurídico concretado mediante una norma dotada de la misma fuerza jurídica que el documento interpretado. En las constituciones rígidas esta interpretación auténtica podrá realizarse a través de leyes interpretativas de la Constitución, en el caso que la propia Carta Fundamental las prevea, como es el caso de Chile, de acuerdo al artículo 66 de la Constitución, sin perjuicio del control preventivo obligatorio de constitucionalidad a que ellas son sometidas.

En una tercera aproximación, se puede considerar auténtica la interpretación constitucional realizada por un órgano cuya interpretación no pueda ser contradicha o modificada por otro órgano y tal decisión sea vinculante para todos los órganos. Tal es el caso del Tribunal Constitucional cuya competencia es decir la última palabra en materia de interpretación de la Constitución, incluso, realizando un control preventivo obligatorio de constitucionalidad de las leyes interpretativas de la Constitución en forma obligatoria antes de su entrada en vigencia como ocurre en el caso chileno, de acuerdo al artículo $93 \mathrm{~N}^{\circ} 1$ de la Constitución."

12 En nuestro medio, Mario Verdugo denominó a este desarrollo infraconstitucional "leyes complementarias o reglamentarias" y señaló: "Reiteramos que a través de estas normas sólo se persigue reglamentar un principio básico, desarrollando sus consecuencias, pero en ningún caso aclarar un precepto obscuro o contradictorio del ordenamiento jurídico superior. Como bien dice Sergio Galaz Ulloa, "de acuerdo con el principio de ordenación jurídica que caracteriza el Estado de Derecho, estas leyes deben conformarse a los principios básicos que sienta la Carta Fundamental; o sea, deben guardar perfecta concordancia y armonía con la super-legalidad". " ("El principio de la Supremacía Constitucional y las Leyes Complementarias o Reglamentarias", Gaceta Jurídica, $\mathrm{N}^{\circ} 16$ (1978), pp. 10-13.)

13 Kelsen, Teoría, cit. nota n. 2, pp.349 y ss.

14 Betti, Emilio, La interpretación jurídica. Páginas Escogidas, (compilación y traducción A. Vergara B.). Editorial Lexis Nexis, Santiago, 2006, p. 57. También del mismo autor "Interpretación de la ley y de los actos jurídicos", Ed. Revista de Derecho Privado, Madrid, 1975. 
normativo, dado un marcado carácter declarativo de su estructura y por regla general tiene un efecto retroactivo. Así se entiende usualmente que la ley interpretativa "tiene por finalidad aclarar las dudas surgidas por oscuridad o insuficiencia de otro texto legal. Como ley posterior y por su finalidad, predomina la ley interpretativa, siempre que provenga del mismo órgano legislativo y reúna iguales requisitos que la ley interpretada, ya que viene a ser una reforma o mejora de ésta"15.

La interpretación auténtica vía ley interpretativa es excepcional frente a la interpretación usual y doctrinal, y se emplea para "[...] rectificar discretamente la mala redacción de una ley, poner coto a una interpretación equivocada o indeseable de los tribunales o simplemente estrechar el ámbito de libertad dejado al intérprete, y que se ha develado excesivo o peligroso"16. En el fondo el interés práctico de la ley interpretativa, está en excluir el carácter de una nueva disposición (non dat, sed datum significat) otorgándole así, implícitamente efecto retroactivo al sentido delimitado o precisado que se autoriza, sea más restringido o más amplio, pero siempre distinto del que podría obtenerse de la misma norma. Por ello no es casual que para la doctrina francesa la ley interpretativa es sinónimo de ley supletoria y de efecto retroactivo (H. Capitant).

La doctrina jurisprudencial de la Corte Suprema acerca del concepto de ley interpretativa en general, se resume del modo siguiente:

a.- La jurisprudencia de este Tribunal ha indicado que: "aunque la legislación positiva no define la ley interpretativa o declarativa, la doctrina generalmente aceptada entiende por tal la ley que se propone aclarar o determinar el sentido dudoso, obscuro o controvertido de otra ley" y que "no puede calificarse de interpretativo el precepto que manifiestamente considera una situación no prevista en la ley más antigua" y que "no puede estimarse como ley interpretativa una ley posterior si la existente es de sentido claro, no se presta a dudas y no requiere interpretación". (Corte Suprema, 4 de octubre de 1974 , consid. $25^{\circ}$. R.t. $71,2^{a}$ parte. Sec. $3^{a}$, pág. 189).

b.- “[...] de acuerdo con lo que dispone el inciso $2^{\circ}$ del artículo $9^{\circ}$ del Código Civil, es ley interpretativa aquella que se limita a declarar el sentido de otra ley y deberá entenderse incorporada en la ley interpretada, o sea, que

\footnotetext{
15 Ossorio y Florit, M. y G. Cabanellas, G, Diccionario de Derecho. Editorial Heliastra, Buenos Aires, 2007 , Vol. II, p. 49-50; y de Capitant, Henri, Vocabulario Jurídico. Ediciones Depalma, Buenos Aires, 1986. También Ducci Claro, Carlos, Interpretación Jurídica. $3^{\circ}$ Ed. Editorial Jurídica de Chile, Santiago, 2006, pp. 39-43. 
Constitución y ley interpretativa. Algunas notas sobre una paradoja y peligros relativos a este tipo de ley Constitution and statute interpretative. Some notes concerning an paradox and dangers relative to be statute type

únicamente precisa su sentido y alcance y viene a fijar el sentido incierto de la antigua:

Que todos los autores y la jurisprudencia de este Tribunal confirman esta tesis: así, entre los tratadistas nacionales, don Luis Claro Solar manifiesta que las leyes interpretativas "no son más que una declaración del sentido de una ley que se presta a dudas. Al decidir cómo entenderse una ley interpretada, el legislador se limita a reiterar su voluntad ya existente, no a hacer una nueva declaración de su voluntad". Los señores Alessandri y Somarriva sostienen que las leyes interpretativas contienen una declaración del sentido de una ley que se presta a dudas, y agregan: "Para que una ley pueda calificarse de realmente interpretativa, debe limitarse a declarar el sentido de otro precedente, pues si contiene normas nuevas o diversas, no puede atribuírsele tal carácter"; y este Tribunal ha dicho en sentencias reiteradas que "no puede calificarse de interpretativo el precepto que manifiestamente considera una situación no prevista en la ley más antigua y que no puede estimarse como ley interpretativa una ley posterior si la existente es de sentido claro, no se presta y no requiere interpretación". (Corte Suprema, 11 de octubre de 1976 , consid. $14^{\circ}$ y $1^{\circ}$. R.F.M. $\mathbf{N}^{\circ}$ 215, pág. 236; Corte Suprema, 30 de agosto de 1976, consid. $7^{\circ}$. R.F.M. No $^{\circ} 213$, pág. 169. En el mismo sentido: Corte Suprema, $1^{\circ}$ de septiembre de 1980 , consid. $7^{\circ}, 2^{\mathrm{a}}$ parte, sec. $1^{\mathrm{a}}$, pág. 163 ).

Asimismo, la doctrina jurisprudencial del Tribunal Constitucional acerca de la "ley interpretativa" de la Constitución en particular muy sumaria en esta materia señala:

"No corresponde, por medio de una ley interpretativa de una norma constitucional agregar nuevos elementos a lo que ésta indica e introducir conceptos que no han sido siquiera insinuados por la Carta Fundamental. Ello implicaría una modificación de la disposición constitucional. Por medio de una ley interpretativa sólo cabe proporcionar claridad o precisión a la redacción de una norma constitucional, cuando su propio texto sea susceptible de originar confusión o desentendimiento, para asegurar con esa interpretación su correcta, uniforme, armónica y general aplicación”. (STC Rol No 158, cons. $\left.\mathbf{6}^{\mathbf{0}}\right)$.

En la doctrina científica nacional han abordado el estudio acerca de la naturaleza y concepto de "ley interpretativa" de la Constitución los profesores Silva Bascuñán y Cea Egaña ${ }^{17}$.

17 Silva Bascuñán, Alejandro, Tratado de Derecho Constitucional. $2^{\mathrm{a}}$ Ed. Tomo VII. Editorial Jurídica de Chile, Santiago, 2000, pp. 39-57 e "Interpretación de la Carta a través del Legislador", Gaceta Jurídica, No 42, 1983 , pp. 8-18 
Por vía ejemplar en nuestro medio Silva Bascuñán sobre la "ley interpretativa" de la Constitución señala: "Una ley interpretativa ha de referirse, según el artículo $82, N^{o} 1$, (actual artículo $93 \mathrm{~N}^{\circ} 1$ ), específica y particularmente a "algún precepto" de su normativa. Se trata, pues, aquí de la interpretación explícita, deliberada, intencional, proveniente de los órganos colegisladores, llamada a generar efectos de carácter general, obligatorios para autoridades y gobernados.

Este tipo interpretativo se diferencia así, por otra parte, según su propia naturaleza, tanto del que tiene fuerza jurídica sólo para los casos particulares-como el que practica la Corte Suprema-, como del que carezca de imperatividad jurídica, por provenir únicamente del esfuerzo exegético propio de la docencia, de los comentarios de las autoridades o del público, o del sustentado en los trabajos de investigación o exposiciones relativos al derecho vigente".

Añade acerca del contenido de la "ley interpretativa" de la Constitución Silva Bascuñan: "Las leyes interpretativas constitucionales han de representar, en efecto, una forma de precisar o esclarecer el alcance de determinado precepto de la Carta. Sólo tienen cabida en aquellos sistemas jurídicos que, como el nuestro, se fundan en el constitucionalismo escrito. No son concebibles en los regímenes de cartas consuetudinarias, en los cuales lo sustantivo constitucional deriva racionalmente de su intrínseca materia ordenativa. Los problemas e interpretación constitucional son de diversa índole de aquellos que plantea la reforma de un precepto de tal jerarquía que se encuentre vigente; ésta, en la mayoría de los regímenes constitucionales, debe someterse a las reglas pertinentes del procedimiento de reforma de la Carta"18.

Agrega sobre los alcances de la interpretación por esta vía legal, Silva Bascuñan:

"La cuestión que nos ocupa gira, entre tanto, en torno a la interpretación por el mismo legislador de un texto constitucional vigente y que se introduzca, como ya dijimos, como una declaración auténtica y forzosa sobre el exacto contenido ordenativo de determinado precepto de tal categoría y jerarquía. Dando a la hermenéutica derivada de la simple consideración y explicación de una norma constitucional, gobernantes y gobernados, en cuanto cumplen y concretan en los hechos la voluntad del constituyente, en cierto modo, la interpretan. Insensiblemente, en efecto, como consecuencia de la evolución de las sociedades, se va atribuyendo a la letra de los preceptos de la Carta una significación que genera variaciones de importancia, sobre todo en orden a la traducción de valores 
Constitución y ley interpretativa. Algunas notas sobre una paradoja y peligros relativos a este tipo de ley Constitution and statute interpretative. Some notes concerning an paradox and dangers relative to be statute type

o determinación de finalidades, como podría ocurrir, por ejemplo, respecto de los conceptos de democracia, libertad, indemnización, etc" 19 .

Finalmente, Silva Bascuñán plantea que la posición jerárquica de las "leyes interpretativas" es afirmada como superior a las leyes, ya que queda "[...] intelectual y sustancialmente confundida y sumida en la misma Carta Fundamental”; por lo que se alega de las leyes interpretativas aludidas en el artículo $3^{\circ}$ del Código Civil, llegándose a confundir o difuminar los ámbitos competenciales de la potestad constituyente y de la potestad legislativa. Sostiene en este orden de ideas críticamente Silva Bascuñán:

"Si se parte de la base, como lo hace la letra del actual texto, de la posibilidad de modificar o derogar una ley interpretativa de la Constitución, ese presupuesto no guarda armonía, a nuestro juicio, con el contexto de la Carta Fundamental, puesto que, conforme a ésta, por una parte, la actuación del Poder Constituyente para reformar la Carta es sumamente compleja, y, por otra, al aceptar que las leyes interpretativas de la Constitución puedan ser modificadas o derogadas, los cambios sustanciales de su contenido resultan sumamente sencillos, lo que es contradictorio con el postulado de certeza, estabilidad y supremacía del constitucionalismo, fundamento de nuestro sistema jurídico" ${ }^{20}$.

Por último, Silva Bascuñan intuye que se desdibuja y hace inútil el poder constituyente originario y en especial el poder constituyente derivado, con lo que la reforma constitucional pierde todo sentido si la "ley interpretativa" fija el sentido y alcance de una norma constitucional, la que puede a su vez ser modificada o derogada por otro cuerpo legal del mismo tipo, estableciéndose una unidad preceptiva y de eventual efecto retroactivo, propia de la lógica de la interpretación auténtica puramente legislativa.

Por lo demás en nuestra historia política sobran ejemplos de leyes interpretativas de dudoso alcance, a saber: Ley N ${ }^{\circ} 6.922$ de 1941 que definió las funciones o comisiones incompatibles de los parlamentarios, prohibiciones que deben tener como única fuente la Constitución (artículo $3^{\circ}$ ) o la Ley $N^{\circ} 8.707$ denominada de las "Consejerías Parlamentarias" inspirada en un fortalecimiento de la "físcalización parlamentaria", que concluyeron vaciando la Constitución en relación a prohibiciones parlamentarias, afectando gravemente el "principio de separación de poderes". En la época un dictamen del Consejo de Defensa Fiscal de 28 de marzo de 1941, admitió la legitimidad de la Ley $\mathrm{N}^{\mathrm{o}} 6.922$ agregando que sus disposiciones deben entenderse incorporadas y en vigencia desde la fecha de la ley que interpreta. Más reciente es la sentencia del Tribunal Constitucional recaída en el proyecto de ley que interpreta el alcance de la garantía 
del derecho de propiedad, en relación a "pensiones perseguidoras" y su reajustabilidad, sentencia que da cuenta de una interesante disidencia del ministro Enrique Correa Labra. (STC Rol N ${ }^{\circ}$ 12 de 1982).

En otro contexto histórico en nuestro país la ley interpretativa dio origen a un conjunto de aporías acerca de la tramitación y retroactividad de éstas, y que resume Cea Egaña en los términos siguientes: "La controversia giró, invariablemente, en trono al principio, según el cual la ley interpretativa se entendía incorporada en la homónima interpretada y regía desde la fecha de vigencia de ésta. Pues bien, ¿se agotaba la competencia del legislador al dictar una ley interpretativa o era posible que aprobara nuevas leyes sobre idéntica materia?, ¿qué sucedía con dos o más leyes que fijaban, sucesiva y contradictoriamente, el sentido y alcance de una misma norma constitucional?, ¿transformábanse los preceptos legales en constitucionales simplemente porque el Código Civil declaraba que las leyes interpretativas pasaban a formar parte de las leyes interpretadas?, ¿podía la Corte Suprema declarar inaplicable, por inconstitucional, un precepto legal interpretativo en circunstancias en circunstancias que a éste se le suponía ya integrado a la propia Constitución?"21.

A nuestro juicio parte importante de estas aporías o contradicciones y dudas planteadas siguen no teniendo respuesta lógicamente coherente, ya que, las "leyes interpretativas" de la Constitución establecidas en el ordenamiento vigente están insertas en un sistema de fuentes (legislación) que las sitúa subordinadas a la Constitución, pero al mismo tiempo fijando el alcance de la voluntad del constituyente.

\section{IV.- Leyes Interpretativas y Potestades: Naturaleza y posición en el sistema de fuentes}

El estudio sumario de esta materia nos reconduce a la teoría de las fuentes del derecho y a las potestades normativas del Estado, en especial la potestad constituyente y la potestad legislativa, y los principios conforme a los cuales se ordena el sistema de normas, materia que tiene un extraordinario desarrollo en la doctrina contemporánea ${ }^{22}$. Además, debe estimarse que la ley interpretativa como genus por excelencia de la interpretación auténtica, tiene importantes diferencias con la "ley interpretativa" de la Constitución como especie, ya que por una parte perteneciendo ambas al campo de la interpretación auténtica, la "ley interpretativa"

21 Cea Egaña, José Luis, "Bases para la interpretación auténtica de la Constitución”, Revista Chilena de Derecho, Vol. 6, N 1-4 (1979), p. 288.

22 Consultar de la doctrina española a Balaguer Callejón, Francisco, Fuentes del Derecho. 2 Vol. Editorial Tecnos, Madrid, 1991; Pérez Royo, Javier, Las Fuentes del Derecho. Editorial Tecnos, Madrid, 1984; Santamaría Pastor, Juan Alfonso, Principios de Derecho Administrativo. $2^{\circ}$ Ed., 2 Vol. Editorial Centro de Estudios Ramón Areces-CEURA, Madrid, 1998-1999, Vol. I, pp. 153-171; Otto, Derecho, cit. nota n. 1. Consultar en teoría general del derecho a Bobbio, Norberto, Derecho y Lógica. UNAM, México, 1965 y a Soler, Sebastián, Las palabras de la ley. México, 1969. 
Constitución y ley interpretativa. Algunas notas sobre una paradoja y peligros relativos a este tipo de ley Constitution and statute interpretative. Some notes concerning an paradox and dangers relative to be statute type

de la Constitución no puede modificar o alterar la norma iusfundamental interpretada, ya que de lo contrario se puede producir una descontitucionalización y eventual "fraude a la Constitución" al sustituir la interpretación del legislador a la reforma de la Constitución, y por otra parte la interpretación de la Constitución exige que la norma iusfundamental presente imprecisión, oscuridad o falta de claridad, no pudiendo completar su significado (en cuanto a adicionar, rectificar o enmendar la norma iusfundamental interpretada), sino sólo proporcionar "claridad o precisión" a la redacción de la norma, como lo sostiene lúcidamente nuestra jurisprudencia constitucional ${ }^{23}$.

Los conceptos de desconstitucionalización (definida por Bidart como "situación irregular del Estado que en su práctica política pone en vigencia un sistema constitucional distinto al normado en la Constitución escrita") y fraude a la Constitución (definida por Burdeau como "violación de un principio de limitación del poder constituyente instituido que desemboca en una práctica irregular [...]"), son conceptos empleados en este trabajo con plasticidad, para designar el divorcio de la Constitución formal con un sistema constitucional irregular, desligándolos de su tradicional conexión a involuciones autocráticas en los regímenes políticos. La desconstitucionalización es un proceso de degradación de la Constitución normativa, una verdadera patología de la vida política del Estado, ya que pone en vigencia un sistema constitucional distinto del normado en la Constitución formal o escrita, siendo instrumentos usuales de este proceso de falseamiento: la mutación y la ley interpretativa (K. Loewenstein, G.J.Bidart Campos, S. Linares Quintana), pudiendo anteceder a verdaderas crisis o rupturas del orden constitucional. A su vez el "fraude a la Constitución" permite infringir la Constitución, una institución o una norma iusfundamental, al amparo de la Constitución, usando una norma o disposición diversa. El fraude se produce, cuando se quiebra la institucionalización del poder, en su expresión estatal de realización de la "idea de derecho" (G. Burdeau) o simplemente por la "perversión" de la Constitución a través de las autocracias o bien por su "desvalorización", asociada a la erosión de la conciencia constitucional (Loewenstein) ${ }^{24}$.

23 Es relevante recordar que el Anteproyecto de Constitución Política de la República preparado por la Comisión Ortúzar, que repone las leyes interpretativas de la Constitución, previstas en la Constitución de 1828 y 1833 , Cartas que le confieren la defensa de la Constitución al Congreso Nacional, y por ende el control político de constitucionalidad de leyes, disponía en el inciso segundo del artículo 69: "Las leyes que interpreten los preceptos constitucionales no podrán vulnerar el sentido de sus disposiciones y requerirán quórum calificado".

24 Consultar de Burdeau, Georges, su monumental obra, Traité de Science Politique. $1^{\circ}$ Ed. Paris, 1949-1957, 7 Vol., t. III, L.G.D.J., 1950, pp. 264-267 y su manual Droit Constitutionnel et Institutions Politiques (hay traducción de la 18 edición francesa Editora Nacional). $18^{\circ}$ Ed. L.G.D.J., Paris, 1977, pp. 54-56, 90-91. Para el análisis de la desconstitucionalización como proceso y sus causas consultamos a los autores argentinos Bidart Campos, Germán J., Doctrina del Estado Democrático. EJEA, Buenos Aires, 1961, p. 104, y la monumental obra de Linares Quintana, Segundo V., Tratado de la Ciencia del Derecho Constitucional Argentino y Comparado. $2^{\circ}$ Ed., t. I. Edita Plus Ultra, Buenos Aires, 1977-1987, pp. 182-194, y su manual Derecho Constitucional e Instituciones Políticas. $2^{\circ}$ Ed., 3 Vol., t. II. Edita Plus Ultra, Buenos Aires, 1976, pp. 563-566. También Loewenstein, Karl, Teoría de la Constitución, (traducción de la edición alemana y estudio por A. Gallego A.). $2^{\circ}$ Ed., $3^{\circ}$ Reimp. Editorial Ariel, Barcelona, 1983, pp. 216-218, 222- 226. 
Arribar a esta definición de la "ley interpretativa" de la Constitución, es resultado de situar este tipo específico de ley en la teoría de las fuentes formales del derecho y tratar a éste como un sistema de normas. En cuanto a las fuentes formales la ley es una fuente que goza de primariedad, aunque la Constitución no recepciona un concepto unívoco de ley, a lo sumo una tipología en el artículo 66 que desglosa las figuras o tipos siguientes: ley interpretativa de la Constitución, ley orgánica constitucional, ley de quórum calificado y ley ordinaria, gozando todas ellas de la misma jerarquía normativa al ser fruto de la potestad legislativa, como lo confirma nuestra jurisprudencia constitucional, por lo que sus diferencias arrancan del principio de competencia y de especialidad procedimental. A esta tipología se suma la ley de quórum calificadísimo (artículo $63 \mathrm{~N}^{\circ} 16$ ), la ley delegatoria (artículo 64) y la creación jurisprudencial de la "ley de bases".

Desde el punto de vista de las normas que componen el sistema jurídico, las relaciones de tales normas se verifican en cuatro dimensiones: vertical, horizontal, de profundidad y temporal, correspondiendo a estas los principios de jerarquía normativa, competencia, procedimiento y sucesión cronológica respectivamente (Santamaría Pastor) ${ }^{25}$.

En este cuadro la ley como genus y la ley interpretativa como specie se sitúan jerárquicamente en la posición o grada propia de la ley, fuente primaria del sistema e infraconstitucional. Materialmente la "ley interpretativa" de la Constitución concierne a un precepto constitucional determinado impreciso, oscuro o confuso, competencialmente se sitúa en el dominio de la ley, pero ordenado a una finalidad precisa, en la medida que es fruto de la potestad legislativa, y procedimentalmente se somete a un quórum especial de tres quintas partes de diputados y senadores en ejercicio para su aprobación, modificación o derogación.

De lo expuesto, podemos colegir que la "ley interpretativa" de la Constitución tiene una posición jerárquica de ley, y dado su contenido preceptivo material, es competencialmente limitada (fijar el sentido y alcance de un precepto impreciso, oscuro o falto de claridad, o como dice nuestra jurisprudencia constitucional proporcionar "claridad o precisión" a la redacción de la norma), aunque posee unidad de significado con la norma iusfundamental interpretada, sin que ello pueda importar modificar o alterar la norma iusfundamental. Luego, discrepamos de aquella caracterización de la "ley interpretativa" de la Constitución realizada por Cea Egaña: "[...] interpretación auténtica, de carácter general y cuyo contenido se entiende incorporado al Código Político interpretado", en la medida que ello quiebra el sistema de fuentes afincado centralmente en un principio de jerarquía normativa ${ }^{26}$.

25 Consultar para el estudio de las fuentes y sus principios ordenadores el texto de Santamaría, Principios, cit. nota n. 22, pp. 153-171.

26 Cea Egaña, José Luis, Teoría del Gobierno. Derecho Chileno y Comparado. Ediciones Universidad Católica de Chile, Santiago, 1999, pp. 118-119. 
Constitución y ley interpretativa. Algunas notas sobre una paradoja y peligros relativos a este tipo de ley Constitution and statute interpretative. Some notes concerning an paradox and dangers relative to be statute type

Esto transforma en esencial el control preventivo y obligatorio de constitucionalidad (material, formal y competencial) por el Tribunal Constitucional de este tipo de leyes (artículo $93 \mathrm{~N}^{\circ} 1$ ). Como bien observa Nogueira Alcalá la interpretación auténtica del legislador es "directa”, pero no es una interpretación "definitiva” en razón del control de constitucionalidad. El control de constitucionalidad de las "leyes interpretativas" de la Constitución está llamado a fijar el limitado campo de la interpretación auténtica por el legislador, y con ello, fijar el campo del poder constituyente derivado. Tal control de constitucionalidad, como lo hemos dicho puede referir a los eventuales vicios de constitucionalidad material, formal y competencial de la ley. ${ }^{27}$

Una lectura distinta, como la criticada por nosotros recogiendo a Silva Bascuñan, conduce a señalados yerros y peligros: primero, el vaciamiento legislativo de la Constitución bajo el pretexto de la interpretación auténtica conduce a desconstitucionalizar la Constitución y eventualmente abre la puerta al fraude de la Constitución, haciendo por lo demás inútil la potestad constituyente derivada y el procedimiento de reforma constitucional reglado en el Capítulo XV de la Carta Política.

Otro peligro asociado estrechamente a los anteriores no menor es el quebranto del principio democrático que está en la base del edificio estatal y del plexo de potestades públicas o normativas, y del cual pende el principio de jerarquía normativa, y el quebranto de la supremacía de la Constitución, al quedar expuesta la Constitución a su desconstitucionalización y fraude expresos.

$27 \quad$ Fallos pronunciados por el Excmo. Tribunal Constitucional entre el 4 de mayo de 1981 y el 24 de septiembre de 1985. Ley Orgánica Constitucional del Tribunal Constitucional y Autos Acordados, pp. 43-44: "Resulta preclara la disidencia del ministro Enrique Correa Labra sobre la amplitud del control de constitucionalidad de la ley interpretativa contenida en la sentencia Rol 12 de 16 de julio de 1982, que consigna como fundamentos pertinentes a lo dicho los siguiente: “ $6^{\circ}$ ) Que, por otra parte, la Junta de Gobierno, usando de la Potestad Legislativa, tiene libertad absoluta para enviar al Tribunal el proyecto de ley que considere o califique de interpretativo constitucional, sin perjuicio de la resolución definitiva que dicte el Tribunal sobre la constitucionalidad de alguno o de todos sus preceptos.

Dicho de otro modo, la Junta de Gobierno escoge libremente la materia que considere objeto de ley interpretativa, y no puede el Tribunal excusarse de pronunciarse sobre su constitucionalidad basándose en que la materia escogida no se comprende entre las que pueden ser objeto de dicha ley, porque con este proceder se abstiene de dictar pronunciamiento sobre la constitucionalidad del proyecto, $\mathrm{y}$, sin embargo, controla la materia para fundar su incompetencia, en circunstancias que este control debe hacerlo en el pronunciamiento sobre constitucionalidad, usando de su competencia;

$7^{\circ}$ ) Que, además, el proyecto ha sido presentado por la Junta de Gobierno como un solo todo encuadrado, a su juicio en el ámbito de una ley interpretativa constitucional, y sobre esa totalidad debe recaer el pronunciamiento del Tribunal, declarando la constitucionalidad o inconstitucionalidad de los preceptos sometidos a su dictamen, en cumplimiento de lo dispuesto en el artículo 82 de la Carta Fundamental.

Si el Tribunal procede de este modo, delimita claramente el campo reservado a la ley interpretativa constitucional y el que corresponde a la ley ordinaria, velando, de esta manera, por la pureza legislativa y evitando que se produzca la incertidumbre respecto a la categoría de la ley, en la parte que no se pronuncie por incompetencia o por falta de atribuciones; [...]". 
En nuestro medio, Cea Egaña ha planteado también dudas acerca de los peligros que conlleva la interpretación auténtica, aunque confunde ésta con la mutación constitucional ${ }^{28}$.

En esta misma perspectiva es menester recordar en nuestro medio la lucidez del constitucionalista clásico Jorge Huneeus en su obra La Constitución ante el Congreso, que es muy esclarecedor en el tema de la posición de las "leyes interpretativas" en las coordenadas de la Carta de 1833 en que impera un control político de constitucionalidad de las leyes:

"Refiriéndonos al discurso que entonces pronunciamos y que cita al pié, sostenemos hoy, como tuvimos el honor de sostenerlo entonces, que las leyes interpretativas de la Constitución pueden derogarse por otra ley, sin sujetarse a lo dispuesto para el caso de reforma constitucional por los artículos 165 a 168. Los artículos 40 y siguientes establecen las reglas a que debe sujetarse la formación de todas las leyes. De esas reglas exceptúan los artículos 165 a 168 sólo las referentes a la reforma de la Constitución, sin mencionar ni incluir en la excepción a las leyes interpretativas, a pesar de que acababa de referirse a éstas en el artículo 164. Luego, es claro que tales leyes quedan sujetas a la regla general".

"Sería por otra parte, tan absurdo ante los principios como chocante en el hecho, suponer siquiera que una ley formada como todas y sin sujeción a las reglas especialísimas que es menester observar para dictar un precepto constitucional, adquiriera este último carácter y no pudiera ser modificada o derogada sino como disposición fundamental. ¿A qué clase de lógica obedecería semejante sistema? Aceptado que fuera, podría resultar que una simple ley, so pretexto de llamarse interpretativa, derogara la Constitución, cosa que entre nosotros es de todo punto inadmisible”.

Cea Egaña, "Bases", cit. nota. n. 21, p. 287: "Los cambios constitucionales -que es la digresión aludida- pueden producirse dentro o fuera del marco constitucional regulado por el Código fundamental. Si excluimos las revoluciones y demás alzamientos que, cuando triunfan, conllevan la ruptura de dicho marco y el quebrantamiento de los mandatos de la Constitución, los cambios que restan son, típicamente, las reformas al texto de la Carta (adiciones, supresiones o sustituciones) las mutaciones, es decir, las alteraciones en la realidad de la configuración del Poder, de la estructura social o del equilibrio de intereses, permaneciendo intacto el texto de la Constitución. Tales mutaciones obedecen, a menudo, a la necesidad de satisfacer nuevas demandas de la comunidad que se consideran obstruidas por la rigidez del procedimiento de reforma constitucional, en especial cuando existen las llamadas cláusulas pétreas e irreformables sobre cuya debatible legitimidad en esta ocasión no nos pronunciamos. Pues bien, la interpretación auténtica y extensiva de la Constitución, efectuada por el legislador ordinario con ánimo actualizador, es, en nuestro juicio, un caso de mutación constitucional, circunstancia que no excluye la posibilidad que por esa vía se cometan fraudes a la Carta. De lo cual se colige que si el Poder Constituyente delega en el Poder Legislativo la facultad de interpretar los mandatos del primero, simultáneamente ha de trazarle los límites sustantivos y procesales que reduzcan en lo posible el eventual falseamiento del sentido objetivo de los principios y normas de la Constitución." 
Constitución y ley interpretativa. Algunas notas sobre una paradoja y peligros relativos a este tipo de ley Constitution and statute interpretative. Some notes concerning an paradox and dangers relative to be statute type

También refiriéndose a la naturaleza de las “leyes interpretativas” Huneeus agrega:

"No se puede argumentar en contra de nuestra opinión con el artículo $9^{\circ}$ del Código Civil, pues él, como lo hemos dicho ya al ocuparnos del artículo 133 de la Constitución, es simple ley y no precepto constitucional; es valla para el juez, pero no para el legislador. Este último no reconoce más trabas en el ejercicio de sus funciones legislativas que las que la Constitución le impone, y desde que ésta no le impone la de no poder reformar o derogar las leyes interpretativas en la misma forma que todas las otras, menos únicamente las de reforma constitucional, es tan claro como la luz del día que puede hacerlo sin el más mínimo embarazo"29.

\section{V.- Algunas Conclusiones}

Para concluir es menester retomar los términos del informe pedido (artículo $2^{\circ}$ del proyecto de ley que establece medidas contra la discriminación ${ }^{30}$ ) y que sirve de base al presente trabajo. Las conclusiones que recogimos sobre el carácter interpretativo del precepto, es un buen ejemplo del reducido campo que posee la "ley interpretativa" de la Constitución, frente a la ley como fuente primaria del ordenamiento jurídico y principal fuente de desarrollo de las normas constitucionales. Ocurre que la "ley interpretativa" de la Constitución es una categoría o tipo excepcional, cuyo contenido acotado (interpretación auténtica) la hace material y competencialmente limitada, luego es la legislación como género la vía ordinaria de desarrollo normativo infraconstitucional. Huelgan los ejemplos acerca de la excepcionalidad de la "ley interpretativa" de la Constitución, ya que se han dictado en el periodo de vigencia de la actual Carta en muy escaso número: Ley $\mathrm{N}^{\circ} 18.152$ (reajustabilidad de pensiones), Ley $\mathrm{N}^{\circ} 18.799$ (residencia de candidatos a parlamentarios) y Ley $\mathrm{N}^{\circ} 19.174$ (elección de consejeros regionales).

Inclusive tratándose de las leyes interpretativas a que refiere tradicionalmente el artículo

Huneeus, Jorge, La Constitución ante el Congreso. 2 Vol., t. II. Imprenta Los Tiempos, Santiago, 1879- 1880, pp. 421-422.

30

“Artículo $2^{\circ}\left(3^{\circ}\right)$.- Para los efectos de esta ley, se entenderá por acto o conducta de discriminación arbitraria toda forma de distinción, exclusión, restricción o preferencia, cometida por agentes del Estado o particulares, que prive, perturbe o amenace el ejercicio de los derechos establecidos en la Constitución Política de la República , en la ley, así como en los Tratados Internacionales ratificados por Chile y que se encuentren vigentes, en particular cuando aquellas se encuentren fundadas en motivos tales como la raza o etnia, la nacionalidad, la situación socioeconómica, el lugar de residencia, el idioma, la ideología u opinión política, la religión o creencia, la sindicación o participación en asociaciones gremiales, el sexo, el género, la orientación sexual, el estado civil, la edad, la filiación, la apariencia personal, la enfermedad o discapacidad.

Sin perjuicio de lo establecido en el artículo $2^{\circ}$ de la ley $N^{\circ} 19.638$, las distinciones, exclusiones, restricciones o preferencias que las entidades religiosas realicen de acuerdo a las actividades mencionadas en los artículos $6^{\circ}$ y $7^{\circ}$ de la misma ley, no se considerarán arbitrarias”. 
$3^{\circ}$ del Código Civil, nuestra jurisprudencia judicial de la Corte Suprema con buen criterio por su alcance, efectos temporales y en aras de la seguridad jurídica señala que para que la interpretación de una ley dada por el legislador y adquiera los caracteres de obligatoria, es menester que aparezca en la ley interpretativa la intención de declarar el sentido de otra (RDJ, t. 30 , sec. $1^{\text {o }}$, p. 93; RDJ, t. 34 , sec. $1^{\mathrm{a}}$, p. 127) y adicionalmente señala que para estar presentes ante una interpretación auténtica debe considerarse que esa calificación la da la doctrina a aquellas leyes que, sobre un punto controvertido de interpretación, consagran una solución que también habría podido adoptar la jurisprudencia (idem F. M. No 86, 1966, p. 335). En el fondo, esta doctrina jurisprudencial da cuenta de cierta desconfianza del tribunal de casación, máximo intérprete de la ley, garante del principio de legalidad y de la cosa juzgada, hacia la interpretación auténtica del legislador, la que no está exenta de problemas.

En efecto en la materia tratada y que tiene como pretexto la consulta camaral relativa al artículo $2^{\circ}$ del proyecto de ley antes citado en este apartado, a su respecto no se divisa que revista caracteres de "ley interpretativa" de la Constitución, dado no sólo el significado consolidado del principio de igualdad constitucional y de la garantía de interdicción de la discriminación arbitraria, sino simplemente, a nuestro juicio el precepto del artículo $2^{\circ}$ comentado, es una norma o ley de desarrollo de la Constitución, encuadrable en el tipo de ley ordinaria y que versando sobre derechos fundamentales y sus garantías (artículo $19 \mathrm{~N}^{\mathrm{o}} 2$ ), quedan a resguardo de la potestad estatal expresada en la ley formal-material a través de las garantías normativas de reserva legal y de aseguramiento del contenido esencial (artículo 19 $\mathrm{N}^{\circ}$ 26), garantías susceptibles de tutela judicial a través de los controles de constitucionalidad residenciados en el Tribunal Constitucional.

Por otra parte, a nuestro ordenamiento jurídico se han incorporado tratados solemnes y multilaterales del sistema ONU, que en cuanto fuentes infraconstitucionales tienen aplicación preferente en nuestro ordenamiento jurídico, aplicación preferente cualificada por la garantía institucional del artículo $5^{\circ}$ inciso $2^{\circ}$ de la Constitución, tratados que le han conferido significado preciso al principio de discriminación arbitraria, y que han recepcionado el principio de discriminación inversa o compensatoria, a saber: artículo $1^{\circ}$ Convención relativa a la lucha contra las discriminaciones en la esfera de la enseñanza (1960-1971), artículo $1^{\circ}$ de la Convención internacional sobre la eliminación de todas las formas de discriminación racial (1965-1971), artículo $1^{\circ}$ de la Convención sobre eliminación de todas las formas de discriminación contra la mujer (1979-1989), artículo $2^{\circ}$ y 28 de la Convención sobre derechos del niño (1989-1990), entre otros instrumentos. Tales definiciones y estándares discriminatorios son un antecedente relevante para la legislación de desarrollo de esta importante garantía constitucional.

Por último, no está demás subrayar que las anotadas paradojas y peligros en torno a la "ley interpretativa" de la Constitución subsisten. La paradoja es el empleo de la ley para interpretar un precepto constitucional, cuando la ley tiene fines y estructura normativa interna distinta a la Constitución. Los peligros anotados rondan como una sombra (al ralentizar o 


\begin{abstract}
Constitución y ley interpretativa. Algunas notas sobre una paradoja y peligros relativos a este tipo de ley Constitution and statute interpretative. Some notes concerning an paradox and dangers relative to be statute type
\end{abstract}

simplemente impedir el ejercicio del poder constituyente derivado) a la "ley interpretativa" de la Constitución: el vaciamiento de la norma iusfundamental, la desconstitucionalización, cuando no el peligro de fraude de la Constitución y la inutilización del procedimiento de reforma constitucional. Además, el recurso a la "ley interpretativa" de la Constitución, dada su excepcionalidad y límites, debe darse previo agotamiento de las reglas hermenéutico constitucionales por los operadores jurídicos frente a los problemas que estos enfrentan.

Finalmente, la "ley interpretativa" de la Constitución se inserta en el dualismo continuidad/ cambio, dualismo que engarza directamente con dos dimensiones de la Carta: primero, su "pretensión de estabilidad", cualidad del orden jurídico fundamental que importa rigidez en las constituciones escritas; y, segundo, su "pretensión de dinamicidad", que abre a la Constitución a los necesarios cambios políticos. En el "núcleo duro" caracterizador de la Constitución quedan sus componentes estructurantes o decisiones fundamentales (régimen político, forma de Estado, concepción de Estado, entre otros); fuera de este "núcleo duro", tenemos el estatuto jurídico de lo político, con horizontes temporales diferenciados (Gomes Canotilho, García Pelayo), que captan la dinamicidad, asegurando el consenso intergeneracional y evitan el distanciamiento entre la Constitución escrita formal y la material ${ }^{31}$.

De la manera expuesta, la Constitución concebida como un ordenamiento marco y abierto, un orden jurídico fundamental, y no un código constitucional exhaustivamente regulador, encuentra en la "reforma constitucional" y en la "interpretación constitucional", las vías de su actualización y "concretización"; y en este cuadro la "ley interpretativa" de la Constitución es un instrumento excepcional como se ha dicho y no exento de paradojas y peligros. Subyace a lo expuesto una consecuencia propia de constituciones democráticas, en orden a que su carácter abierto y techo ideológico plural, permite que el sistema jurídico- político (dinámica, cambio y adaptación) refleje las opciones políticas concretas en cada momento histórico; con lo cual el lenguaje escrito de la Constitución que arrastra problemas de ambigüedad (semántica, sintáctica y contextual), vaguedad (intencional, extensional, combinatoria, gradual, etc), de "textura abierta", entre otros; en su indeterminación, incomplitud, apertura, resulta virtuoso o útil simplemente, ya que posibilitan el consenso intergeneracional bajo un "gran paraguas", en que el desarrollo infraconstitucional e interpretación constitucional queda abierta a los poderes públicos y operadores jurídicos, y lo que es más importante a la ciudadanía, partidos y movimientos en un espacio público de deliberación acerca de lo político constitucional ${ }^{32}$.

31 Consultar a Gomes Canotilho, José J., Teoría de la Constitución, (trad. C. Lema Añón). Editorial Dykinson, Madrid, 2003, pp. 101-102. También un libro clásico de la década de 1950 de García Pelayo, Manuel, Derecho Constitucional Comparado. Alianza Editorial, Madrid, 1984, pp. 128-137.

32 Consultar a Aguiló, Josep, La Constitución del Estado Constitucional. Editorial Temis- Palestra, Colombia, 2004, pp. 135-146. También es de utilidad la monografía de Moreso, Juan José, La indeterminación del Derecho y la interpretación de la Constitución. CEPC, Madrid, 1997. También a Santamaría, Principios, cit. nota n. 22, pp. 181-191. 